\title{
How Can Manual Rotation Reduce Vacuum, Forceps and Caesarean Deliveries? -A Review of the Evidence
}

\author{
Cathrine $0 \mathbf{s}^{1,2}$, Elisabeth Severinsson ${ }^{1}$ \\ ${ }^{1}$ The Centre for Women's, Family \& Child Health, Department of Nursing and Health Sciences, Faculty of Health and Social \\ Sciences, University College of Southeast-Norway, Kongsberg, Norway \\ ${ }^{2}$ Oslo University Hospital, Ullevål, Oslo, Norway \\ Email: cathrine.os@gmail.com
}

How to cite this paper: Os, C. and Severinsson, E. (2017) How Can Manual Rotation Reduce Vacuum, Forceps and Caesarean Deliveries?-A Review of the Evidence. Open Journal of Nursing, 7, 68-85. http://dx.doi.org/10.4236/ojn.2017.71007

Received: December 13, 2016

Accepted: January 15, 2017

Published: January 18, 2017

Copyright $\odot 2017$ by authors and Scientific Research Publishing Inc. This work is licensed under the Creative Commons Attribution International License (CC BY 4.0).

http://creativecommons.org/licenses/by/4.0/

\begin{abstract}
The aim of this review was to investigate whether manual rotation can be used to reduce vacuum, forceps and caesarean deliveries in women with occiput posterior or occiput transverse positions from $7 \mathrm{~cm}$ dilation in labour. A search strategy was developed and relevant papers published between 1946 and January 2015 were identified from electronic databases. Key search terms used were manual and digital rotation, labour presentation, obstetric labour complications, occiput posterior and version foetal. The search revealed 330 papers. A short list of 33 publications of possible relevance was compiled and assessed using the following criteria: primary studies on the effectiveness of manual rotation performed in women with singleton occiput posterior or occiput transverse presentations published in English or the Scandinavian languages. The quality of the included studies was evaluated by means of the critical appraisal tools for quantitative studies. Seven studies were included in the thematic analysis. The results varied but the main finding was that in order to decrease vacuum, forceps and caesarean deliveries by means of manual rotation, it is essential that the procedure is successful. The success rate of manual rotation is dependent on the experience of the healthcare professionals who perform the rotation procedure rather than the technique employed. Predictors of successful manual rotation were used after engagement of the foetal head, at full dilatation and prophylactic use before failure to progress in labour. In conclusion, although the results vary, there is a consensus in all the studies that manual rotation is worth considering and that it can contribute to decreasing vacuum, forceps and caesarean deliveries. The implications for practice are that successful manual rotation can reduce caesarean delivery and increase spontaneous vaginal delivery, but experience is necessary to perform successful rotations. Because there are no risk factors associated with manual
\end{abstract}


or digital rotation when performed after engagement of the head and at full dilatation, they are worth considering. The central role of the midwife in each individual labour makes her important for ensuring that manual rotation can be considered at the right time in labour.

\section{Keywords}

Literature Review, Midwifery, Manual and Digital Rotation, Labour

Presentation, Occiput Posterior

\section{Introduction}

Occiput posterior (OP) and Occiput transverse (OT) positions have been associated with difficult labours for centuries [1]. For this reason, Dr William Smellie conducted and reported the first instrumental rotation from an OP to an Occiput Anterior (OA) in 1745 [2]. The benefits of rotating the foetus have been debated ever since, although it is well known that OP presentations represent a great risk [1] [3] [4] [5].

The instrumental rotation forceps and instrumental delivery in general have been associated with many serious complications such as the $3 \mathrm{rd}$ and 4 th degree lacerations, postpartum haemorrhage and neonatal morbidity, despite the fact that with appropriate training, the techniques can be performed safely [6] [7]. Manual rotation (MR) is a procedure where the whole hand is used to manually flex and rotate the foetus from an OP or OT to an OA presentation [8]. Digital rotation (DR) is when only the fingers are used to perform the rotation [9]. However, MR is the general term and will be used throughout the paper.

The MR technique was first documented in 1888 [10]. The procedure is employed as a technique to ensure that the head of the foetus is in a good position for application of the forceps [11]. For that reason, MR may have been associated with the risks involved in instrumental manoeuvers. However, it is a safe, effective and low cost procedure that increases the chance of vaginal delivery [12] [13] [14].

It has been reported that the incidence of OP and OT positions in the first stage of labour is $33.9 \%$ and $27.7 \%$ respectively [15]. In the second stage, $19 \%$ of foetuses are still in an OP position and $16.7 \%$ in an OT position [15]. Although most foetuses in an OP position rotate spontaneously, 5.5 to $8.3 \%$ have been reported to remain in persistent occiput posterior (POP) position [5] [16]. Of these, $68 \%$ require a vacuum delivery (VD), Forceps delivery (FD) or Caesarean delivery (CD) [3]. The CD rate in Norway and worldwide has risen over the last three decades [17]. In 2013 every sixth child born in Norway was delivered by $\mathrm{CD}$, which is about 10,000 children a year [18].

There is a significantly increased risk of maternal morbidity associated with CD compared with spontaneous vaginal delivery. Complications occur in $21 \%$ of all CD patients [18], the most common of which are postpartum bleeding and 
infections. Other complications are trauma to the bladder and intestines. A woman who underwent a CD has a $45 \%$ increased risk of another CD in subsequent labours [18]. Perhaps the greatest problem with undergoing a $C D$ is the complication that can cause in subsequent pregnancies and labours such as miscarriages, bleeding during pregnancy, prolonged labour, premature labour and low birth weight. Serious complications reported include uterus rupture, ectopic pregnancy [18], placenta praevia, placenta accrete [19] and intrauterine death [20].

There are several reasons for a $\mathrm{CD}$, making it necessary to consider different approaches for reducing the CD rate. Prolonged labour is the reason for $20.7 \%$ of all emergency CDs in Norway [18]. The reason for prolonged labour is diverse and complex, but mal presentation of the head of the foetus has been recognised as a great risk for dystocia. Of all emergency CDs, $18 \%$ are because of dystocia related to OP presentation [21].

Research has been conducted on how to prevent dystocia and facilitate vaginal delivery, involving active management of labour [22] and one-to-one care in labour [23]. Although the results have not shown a significant reduction of the $C D$ rate, many birth wards base their procedures for ensuring progress in labour on active management of labour research. However, these studies do not take the rotation and presentation of the foetal head into account.

\section{Aim}

The aim of this study was to investigate whether MR can be used from $7 \mathrm{~cm}$ dilation in labour to reduce VD, FD and CD in women with OP or OT positions.

\section{Methods}

\subsection{Inclusion Criteria for This Review}

Studies were selected for inclusion based on the population, intervention, comparison, outcome measures and study design.

Population: Women in labour with a singleton, non-anomalous, live birth. Three of the included studies described rotation of OP positions, while four described rotation of both OP and OT positions.

Intervention: Manual rotation after $7 \mathrm{~cm}$ dilatation.

Comparison: Four of the included studies compared MR with expectant management and three compared successful MR with unsuccessful MR.

Outcome measures: Vacuum, forceps or caesarean delivery.

Study design: Primary studies.

Exclusion criteria were MR or DR used on other cephalic presentations and unpublished literature.

\subsection{Search Methods for Identification of Studies}

The systematic search was conducted in the Medline, Ovid Medline, SveMed+, Cinahl, Cochrane Library, Maternity and infant care and Up To Date databases 
for the period 1946 to January 2015 with guidance from a specialist librarian employed at the Medical Library of Oslo University hospital, Ullevål. The following keywords were employed: manual rotation and digital rotation, labour presentation, obstetric labour complications, occiput posterior and version foetal. The search and findings were reported according to the method described by Aveyard [24]. An example of the search in one of the main databases, Ovid Medline is presented in Table 1.

A total of 330 papers were retrieved from the database search, of which seven were included in the thematic analysis (Figure 1).

\subsection{Data Collection and Analysis}

\subsubsection{Study Selection, Data Extraction and Management}

A list of articles that met the inclusion criteria based on abstracts was compiled. The full texts of these studies and those of possible relevance were retrieved and evaluated in accordance with the inclusion criteria.

The following data were extracted from all selected studies: general information (authors, publication year and country of investigation), aim, design and number of patients. A summary of the included articles is presented in Table 2.

\subsubsection{Quality Assessment}

The seven articles were evaluated using tools from the Critical Appraisal Skills programme (CASP) [25] (Table 3). They included one case control study, two cohort studies and one pilot study. The remaining three were a mix of retrospective and prospective studies with no other definition. The pilot study and the

Table 1. An example of the search in Ovid Medline.

\begin{tabular}{|c|c|}
\hline Searches & Results \\
\hline 1. Version, Foetal/ & 666 \\
\hline 2. exp Labor Presentation/ & 6105 \\
\hline $\begin{array}{l}\text { 3. exp Obstetric Labor Complications/pc [Prevention \& } \\
\text { Control] }\end{array}$ & 7471 \\
\hline 4. occipit*.ti,ab. & 32,247 \\
\hline 5. occiput ${ }^{*}$.ti,ab. & 1448 \\
\hline 6. $\left(\left(\right.\right.$ tranverse or posterior $\left.{ }^{\star}\right)$ adj2 posit $\left.{ }^{\star}\right)$.ti,ab. & 1652 \\
\hline 7. ((tranverse or posterior $\left.{ }^{\star}\right)$ adj2 delivery).ti,ab. & 50 \\
\hline 8. ((tranverse or posterior $\left.{ }^{\star}\right)$ adj2 deliveries).ti,ab. & 9 \\
\hline 9.1 or 2 or 3 or 4 or 5 or 6 or 7 or 8 & 48,043 \\
\hline 10. Rotation/ & 21,642 \\
\hline 11. $\left(\left(\right.\right.$ manual $^{*}$ or digital $\left.{ }^{\star}\right)$ adj4 $\left.\operatorname{rotat}^{*}\right)$.ti,ab. & 492 \\
\hline 12. 10 or 11 & 22,045 \\
\hline 13. 9 and 12 & 282 \\
\hline 14. limit 13 to (Danish or English or Norwegian or Swedish) & 256 \\
\hline
\end{tabular}




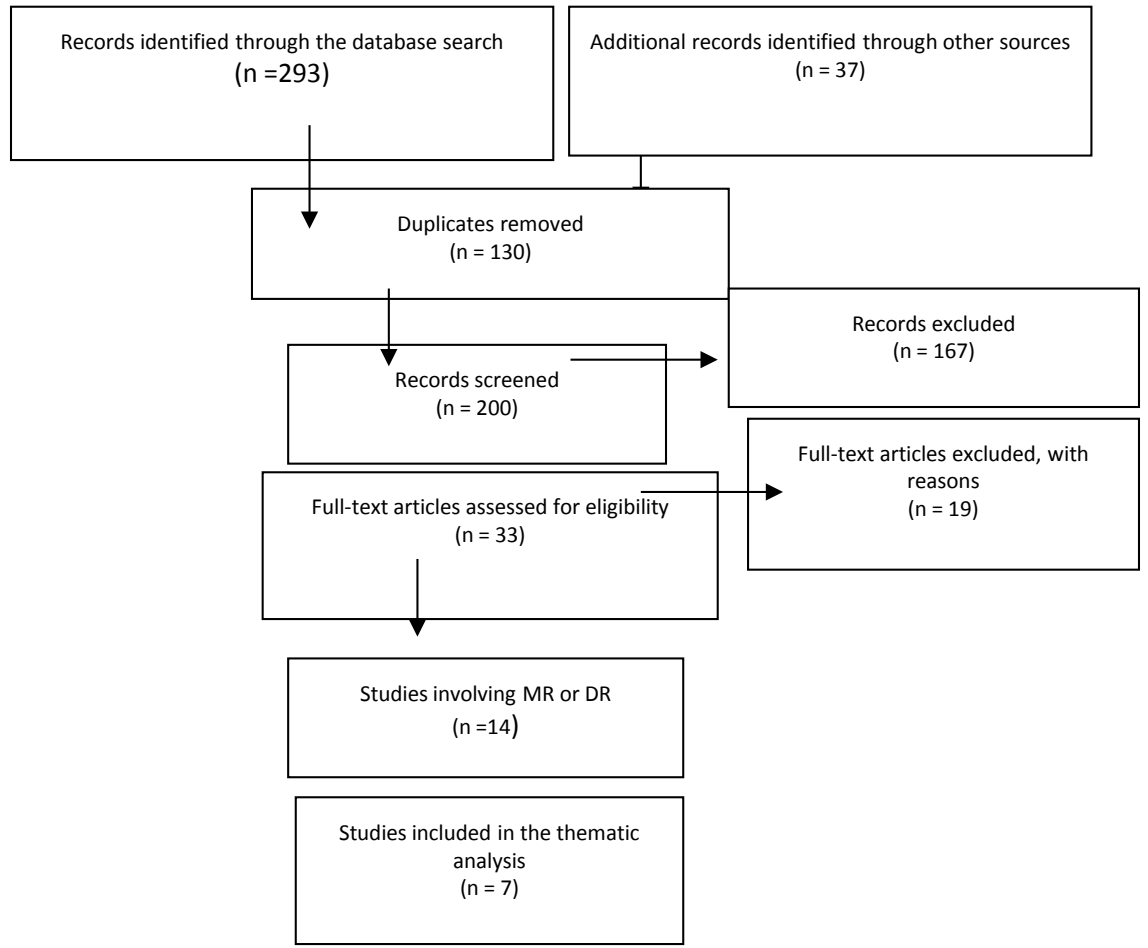

Figure 1. Flowchart of selection of studies for the review.

Table 2. Study characteristics of the included studies quality assessment.

\begin{tabular}{|c|c|c|c|}
\hline $\begin{array}{l}\text { Main author (year) } \\
\text { country }\end{array}$ & Aim of study & $\begin{array}{l}\text { Type } \\
\text { of study }\end{array}$ & Population \\
\hline $\begin{array}{l}\text { Shaffer (2006) } \\
\text { USA }\end{array}$ & $\begin{array}{l}\text { To define predictors of successful rotation and rate of } \\
\text { caesarean delivery after manual rotation of the foetal } \\
\text { occiput from occiput posterior or transverse position }\end{array}$ & $\begin{array}{l}\text { Retrospective cohort } \\
\text { study }\end{array}$ & $\begin{array}{l}742 \text { women met the criteria during the } \\
\text { study period }\end{array}$ \\
\hline $\begin{array}{l}\text { Reichman (2008) } \\
\text { Israel }\end{array}$ & $\begin{array}{l}\text { To study the efficacy of DR in reducing the } \\
\text { prevalence of POP positions and its consequences }\end{array}$ & $\begin{array}{l}\text { Prospective } \\
\text { study }\end{array}$ & $\begin{array}{l}\text { Group 1: without intervention, } 30 \\
\text { women } \\
\text { Group 2: DR or MR, } 31 \text { women }\end{array}$ \\
\hline Shaffer (2011)USA & $\begin{array}{l}\text { To examine mode of delivery and perinatal } \\
\text { outcomes in women with OP or OT position in the } \\
\text { second stage of labour with a trial of MR compared to } \\
\text { expectant management }\end{array}$ & $\begin{array}{l}\text { Retrospective cohort } \\
\text { study }\end{array}$ & $\begin{array}{l}\text { Group1: MR } 731 \text { women } \\
\text { Group2: Expectant management: } 2527 \\
\text { POP or OT positions diagnosed at } \\
\text { delivery }\end{array}$ \\
\hline Le Ray (2013) France & $\begin{array}{l}\text { To assess the effect of a policy of MR on the mode of } \\
\text { delivery of foetuses in OP or OT positions at full } \\
\text { dilatation }\end{array}$ & $\begin{array}{l}\text { Prospective } \\
\text { study }\end{array}$ & $\begin{array}{l}\text { Hospital 1: No MR } 111 \text { women } \\
\text { Hospital 2: MR } 220 \text { women }\end{array}$ \\
\hline Sen (2013) Japan & $\begin{array}{l}\text { To examine the risk factors and management } \\
\text { processes of the POP position by analyzing medical } \\
\text { records from one hospital. }\end{array}$ & Retrospective study & $\begin{array}{l}\text { OP positions in labour: } 103 \\
\text { MR: } 17 \\
\text { Posture change: } 13 \\
\text { The rest: no management } \\
\text { Control group: } 1054 \text { OA positions }\end{array}$ \\
\hline $\begin{array}{l}\text { Graham (2014) Aus- } \\
\text { tralia }\end{array}$ & $\begin{array}{l}\text { To determine the feasibility of a multicentre RCT to } \\
\text { investigate whether DR of the foetal head from OP } \\
\text { position in the second stage of labour reduces the risk } \\
\text { of OD }\end{array}$ & Pilot study & $\begin{array}{l}1004 \text { women consented. } \\
\text { Randomised: } 30 \text {; DR: } 15 \\
\text { Sham procedure: } 15\end{array}$ \\
\hline $\begin{array}{l}\text { Le Ray (2007) } \\
\text { France }\end{array}$ & $\begin{array}{l}\text { To identify the risk factors for failure of MR in } \\
\text { patients with OP or OT positions during labour and } \\
\text { to study the caesarean rate in relation to the success } \\
\text { of the rotation }\end{array}$ & Case-control study & $\begin{array}{l}\text { MR performed on } 796 \text { women. } \\
\text { After randomization: } 79 \text { successful } \\
\text { MR, } 68 \text { failed MR }\end{array}$ \\
\hline
\end{tabular}

Caesarean Delivery $=\mathrm{CD}$, Instrumental Delivery $=\mathrm{ID}$, Manual Rotation $=\mathrm{MR}$, Occiput posterior $=\mathrm{OP}$, Occiput transvers $=\mathrm{OT}$, Operative Delivery $=\mathrm{OP}$, Persistent Occiput Posterior $=$ POP. 
Table 3. Quality assessment of the included studies.

\begin{tabular}{|c|c|c|c|c|c|c|c|c|c|c|c|}
\hline \multicolumn{12}{|c|}{ Quality assessment questions for Cohort studies } \\
\hline \multirow{2}{*}{$\begin{array}{l}\text { Main Author (year) } \\
\text { country }\end{array}$} & \multicolumn{10}{|c|}{ Quality assessment questions* } & \multirow{2}{*}{$\begin{array}{c}\text { Total } \\
\text { assessment } \\
\text { Quality }\end{array}$} \\
\hline & 1 & 2 & 3 & 4 & 5 & 6 & 7 & 8 & 9 & 10 & \\
\hline Shaffer (2006) USA & $\mathrm{Y}$ & $\mathrm{Y}$ & $\mathrm{U}$ & $\mathrm{U}$ & $\mathrm{U}$ & $\mathrm{Y}$ & $\mathrm{U}$ & $\mathrm{Y}$ & $\mathrm{Y}$ & $\mathrm{Y}$ & Medium \\
\hline $\begin{array}{l}\text { Reichman (2008) } \\
\text { Israel }\end{array}$ & $\mathrm{Y}$ & $\mathrm{U}$ & $\mathrm{Y}$ & $\mathrm{Y}$ & $\mathrm{Y}$ & $\mathrm{N}$ & $\mathrm{Y}$ & $\mathrm{U}$ & $\mathrm{Y}$ & $\mathrm{Y}$ & Medium \\
\hline Shaffer (2011) USA & $\mathrm{Y}$ & $\mathrm{Y}$ & $\mathrm{N}$ & $\mathrm{Y}$ & $\mathrm{Y}$ & $\mathrm{Y}$ & $\mathrm{Y}$ & $\mathrm{Y}$ & $\mathrm{Y}$ & $\mathrm{Y}$ & High \\
\hline $\begin{array}{c}\text { Le Ray (2013) } \\
\text { France }\end{array}$ & $\mathrm{Y}$ & $\mathrm{Y}$ & $\mathrm{Y}$ & $\mathrm{Y}$ & $\mathrm{Y}$ & $\mathrm{Y}$ & $\mathrm{Y}$ & $\mathrm{Y}$ & $\mathrm{Y}$ & $\mathrm{Y}$ & High \\
\hline Sen (2013) Japan & $\mathrm{Y}$ & $\mathrm{Y}$ & $\mathrm{N}$ & $\mathrm{Y}$ & $\mathrm{N}$ & $\mathrm{N}$ & $\mathrm{U}$ & $\mathrm{U}$ & $\mathrm{Y}$ & NI & Low \\
\hline $\begin{array}{c}\text { Graham (2014) } \\
\text { Australia }\end{array}$ & $\mathrm{Y}$ & $\mathrm{Y}$ & $\mathrm{Y}$ & $\mathrm{Y}$ & $\mathrm{Y}$ & $\mathrm{Y}$ & $\mathrm{N}$ & $\mathrm{N}$ & $\mathrm{N}$ & NI & Medium \\
\hline \multicolumn{12}{|c|}{$\begin{array}{l}\text { 1) Did the study address a clearly focused issue? 2) Was the cohort recruited in an acceptable way? } \\
\text { 3) Was the exposure accurately measured to minimise bias? 4) Was the outcome accurately } \\
\text { measured to minimise bias? 5) Have the authors identified all important confounding factors? 6) } \\
\text { Was the follow up of subjects complete enough? 7) Do you believe the results? 8) Can the results be } \\
\text { applied to the local population? 9) Do the results of this study fit with other available evidence? 10) } \\
\text { Were ethical issues considered? }\end{array}$} \\
\hline \multicolumn{12}{|c|}{ Quality assessment questions for case-control study } \\
\hline $\begin{array}{c}\text { Le Ray } \\
\text { (2007) France }\end{array}$ & $\mathrm{Y}$ & $\mathrm{Y}$ & $\mathrm{Y}$ & $\mathrm{Y}$ & $\mathrm{U}$ & $\mathrm{Y}$ & $\mathrm{Y}$ & $\mathrm{Y}$ & $\mathrm{Y}$ & & High \\
\hline \multicolumn{12}{|c|}{$\begin{array}{l}\text { Note: } \mathrm{Y}=\mathrm{Yes} ; \mathrm{N}=\mathrm{No} ; \mathrm{U}=\text { Unclear; } \mathrm{NI}=\text { No Information } \\
{ }^{*} \text { Quality assessment questions } \\
\text { 1) Did the study address a clearly focused issue? 2) Did the authors use an appropriate method to } \\
\text { answer their question? 3) Were the cases recruited in an acceptable way? 4) Were the controls se- } \\
\text { lected in an acceptable way? } 5 \text {. Was the exposure accurately measured to minimise bias? 6) Have the } \\
\text { authors identified all important confounding factors? 7) Can you believe the results? 8) Can the } \\
\text { results be applied to the local population? 9) Were ethical issues considered? }\end{array}$} \\
\hline
\end{tabular}

non-defined studies were evaluated by means of the CASP cohort study checklist. The methodical quality was measured on the basis of the CASP questions. The questions with the following response alternatives: Yes, No, Unclear, or No information were applied. The assessment process was inspired by Berg et al. [26].

Explanation of assessment of study quality: High quality: All or almost all of the checklist criteria were met. Unlikely that the conclusions will change. Studies met $>50 \%$ of the criteria. Medium quality: Some of the criteria were not met or the study does not adequately address the criteria. Unlikely that the conclusions will change. Studies met $>50 \%$ or $50 \%$ of the criteria. Low quality: Few or no criteria were met and criteria not adequately addressed. The study conclusions are likely to change. Studies met $<50 \%$ of the criteria. The process of scoring the quality of the studies from high to low was inspired by Berg et al. [26] and discussed with the supervisor. 


\subsubsection{Analysis}

Information from the included articles was summarized in a table and sorted by publication year. A thematic analysis was conducted [24] based on the literature review question "How can $\mathrm{MR}$ reduce $\mathrm{VD}, \mathrm{FD}$ and $\mathrm{CD}$ " and the main findings of each of the included studies.

\section{Findings}

\subsection{Study Characteristics and Methodological Quality}

Seven studies were included in the literature review, none of which was a randomized controlled trial (RCT). There were two Cohort studies [14] [27] one Case-control study [13] and one Pilot study [28]. The rest were a mix of retrospective and prospective studies [29] [30] [31].

The article by Graham et al. [28] is a pilot study. Although it is of medium methodological quality, the results are not be of great importance for this paper due to the small population, that makes the study underpowered to test the efficiency of prophylactic DR. Nevertheless, it is a valuable study because it shows that a large double-blinded multi-centre RCT is feasible. Although the study by Sen et al. [31] was not excluded despite its low methodological quality, papers by Le Ray et al. [13], Le Ray et al. [29] and Shafferet al. [14] were given the highest methodological were prioritised in the thematic analysis. The studies by Shaffer et al. [27] and Reichman et al. [30] were of medium quality.

\subsection{Thematic Analysis}

Six themes emerged: How can MR reduce VD, FD and CD?; Mode of delivery after MR versus expectant management; Mode of delivery after successful or unsuccessful MR; Technique and success rate; Midwives' involvement in the MR; and Predictors of successful or unsuccessful MR.

\subsection{How Can Manual Rotation Reduce Vacuum Delivery, Forceps Delivery and Caesarean Delivery?}

All of the included studies suggest that MR is a procedure to consider for reducing VD, FD and $\mathrm{CD}$ rates.

\section{Interpretations of Findings}

Having studied the conclusions of each study, there is a consensus that MR is a procedure worth considering as it can contribute to reducing VD, FV and CD.

The authors based their reasons for arguing that MR can reduce VD, FD and $\mathrm{CD}$ on two different findings. Reichman et al. [30], Shaffer et al. [14], Le Ray et al. [29] and Graham et al. [28] were influenced by the findings related to mode of delivery after MR versus expectant management.

Shaffer et al. [27], Le Ray et al. [13] and Sen et al. [31] referred to the findings related to mode of delivery after successful versus unsuccessful MR. The results will be presented separately as: mode of delivery after MR versus expectant management (Table 4) and mode of delivery after successful versus unsuccessful MR (Table 5). 
Three of the included studies described rotation of OP positions [28] [30] [31], Four described rotation of both OP and OT positions [13] [14] [27] [29]. Only Le Ray et al. [29] referred to the success rate when comparing rotation from the two positions, although they did not observe any difference in the success of rotations from OT and OP positions.

\subsection{Mode of Delivery after Manual Rotation versus Expectant Management}

Reichman et al. [30] revealed that none of the women who underwent MR had a CD (Table 4). Shaffer et al. [14] reported a CD reduction rate of $32.8 \%$ after MR. Although Le Ray et al. [29] only found a CD reduction rate of $1.7 \%$ after $\mathrm{MR}$, there was a $15.4 \%$ reduction in the operative delivery rate. Both Reichman et al. [30] and Le Ray et al. [29] found an increase in instrumental delivery rates after MR of $27.4 \%$ and $13.8 \%$. Shaffer et al. [14] reported almost identical instrumental delivery rates after MR and expectant management. Reichman et al. [30] and Le Ray et al. [29] found an increase in spontaneous vaginal delivery of $50.1 \%$ and $15.5 \%$ after MR. The study by Graham et al. [28] lacks the power to provide answers on rates.

\section{Interpretations of Findings}

The studies on MR versus expectant management differed in many ways, but an important similarity between Reichman et al. [30], Le Ray et al. [29] and Graham et al. [28] was that the diagnosis of the OP or OT position was made in the second stage of labour.

The expectant management group in the study by Shaffer et al. [14] reported POP positions diagnosed at delivery, which can explain the very high CD rate that might be due to failure to take account of OP position that would have

Table 4. Mode of delivery after MR or expectant management.

\begin{tabular}{cccc}
\hline $\begin{array}{c}\text { Main author } \\
\text { (year) country }\end{array}$ & MR & Expectant management & P-value \\
\hline Reichman & SVD: $24(77.4 \%)$ & SVD: $8(26.4 \%)$ & $\mathrm{P}=0.0001$ \\
(2008) Israel & VD: $7(22.6 \%)$ & VD: $15(50 \%)$ & $\mathrm{P}=0.0001$ \\
Shaffer & CD: 0 & CD: $7(23.3 \%)$ & $\mathrm{P}=0.0001$ \\
(2011) USA & ID: $41 \%$ & ID: $39 \%$ & $\mathrm{P}=0.373$ \\
& CD: $8.6 \%$ & CD: $41.4 \%$ & $\mathrm{P}<0.001$ \\
Le Ray & SVD: $168(76.8 \%)$ & SVD: $68(61.3 \%)$ & $\mathrm{NI}$ \\
$(2013)$ France & ID: $33(15.0 \%)$ & ID: $32(28.8 \%)$ & $\mathrm{P}<0.01$ \\
& CD: $18(8.2 \%)$ & CD: $11(9.9 \%)$ & $\mathrm{P}=0.68$ \\
& OD: $51(23.3 \%)$ & OD: $43(38.7 \%)$ & $\mathrm{P}<0.01$ \\
Graham & SVD: $2(13 \%)$ & SVD: $3(20 \%)$ & $\mathrm{NI}$ \\
$(2014)$ Australia & VD: $6(40 \%)$ & VD: $5(33 \%)$ & $\mathrm{P}=0.70$ \\
& FD: $3(20 \%)$ & FD: $4(27 \%)$ & $\mathrm{P}=1.0$ \\
& CD: $4(27 \%)$ & CD: $3(20 \%)$ & $\mathrm{P}=1.0$ \\
& OD: $13(87 \%)$ & OD: $12(80 \%)$ & $\mathrm{P}=1.0$
\end{tabular}

Caesarean Delivery $=$ CD, Instrumental Delivery $=$ ID, Operative Delivery $=$ OP, Forceps Delivery $=$ FD, Spontaneous Vaginal Delivery $=$ SVD, Vaginal Delivery $=$ VD, Undefined Vaginal Delivery $=$ UVD, NI $=$ No Information. 
spontaneously rotated had they been diagnosed in the second stage of labour. OP positions are associated with a large proportion of emergency CD [18]. Of all emergency CDs, $18 \%$ are due to dystocia related to OP presentation [21].

Shaffer et al. [14] found almost equal instrumental rates after MR and expectant management. The high rate in the expectant management group was no surprise, as all the deliveries involved POP positions, a large proportion of which require a VD, FD or $\mathrm{CD}$ [3]. However, the high instrumental delivery rate in the MR group was not anticipated [14] and could be related to the relatively low success rate of $74 \%$. Furthermore, there is no way of knowing whether the instrumental delivery took place after a successful or unsuccessful rotation. For this reason, there might have been many unsuccessful rotations that led to the need for an instrumental delivery. A high rate in successful MR could be related to the fact that MR corrects the foetal head in the birth canal, making VD or FD easier to implement.

The main results show an increase of spontaneous vaginal delivery after MR. While the $\mathrm{CD}$ and instrumental rates vary, there seems to be an overall decrease in the operative delivery rate after MR (Table 4).

\subsection{Mode of Delivery after Successful or Unsuccessful Manual Rotation}

Le Ray et al. [13] and Shaffer et al. [27] found that women with successful MR had a significantly lower CD rate $(\mathrm{p}<0.001)$ (Table 5$)$. In the study by Sen et al. [31] none of the successful MRs needed a CD.

The instrumental rate reported by Le Ray et al. [13] was higher in the successful MR group, but the difference was not significant.

Le Ray et al. [27] also demonstrated that women with a successful MR had a $50.9 \%$ increase in the spontaneous vaginal delivery rate. Shaffer et al. [27] showed that women who had a successful MR had nearly a three-fourths increase in undefined vaginal delivery.

\section{Interpretations of Findings}

Sen et al. [31] did not analyse MR as an individual procedure, but 17 cases of MR and 13 Posture changes. Although the small population led to a lack of power,

Table 5. Mode of delivery after successful or unsuccessful MR.

\begin{tabular}{cccc}
\hline $\begin{array}{c}\text { Main author (year) } \\
\text { country }\end{array}$ & Successful MR & Unsuccessful MR & P-value \\
\hline \multirow{2}{*}{ Shaffer (2006) USA } & UVD: $97.9 \%$ & UVD: $65.7 \%$ & P $<0.001$ \\
& CD: $2.1 \%$ & CD: $34.3 \%$ & P $<0.001$ \\
Le Ray (2007) & SVD: $53(67.1 \%)$ & SVD: $11(16.2 \%)$ & NI \\
France & ID: $23(29.1 \%)$ & ID: $17(25.0 \%)$ & NI \\
& CD: $3(3.8 \%)$ & CD: $40(58.8 \%)$ & P $<0.001$ \\
Sen (2013) Japan & UVD: $14(100 \%)$ & UVD: $11(69 \%)$ & P $<0.05$ \\
& CD: $(0 \%)$ & CD: $5(31 \%)$ & P $<0.05$ \\
\hline
\end{tabular}

Caesarean Delivery $=$ CD, Instrumental Delivery $=$ ID, Undefined Vaginal Delivery $=$ UVD, NI $=$ No Information. 
the conclusion is interesting. Only eight of the 17 cases had a successful MR, but none of the women with a successful MR needed a CD.

The instrumental delivery rate in Le Ray et al. [13] was higher in the successful MR group, but the difference was not significant, for which no explanation was given. However, it could be due to the fact that MR corrects the foetal head in the birth canal, making VD or FD easier to implement.

It is important to investigate whether the MR was successful or unsuccessful in order to understand the impact of rotation on mode of delivery. The results from the included studies on successful versus unsuccessful MR show a significant reduction in $\mathrm{CD}$ and an increase of spontaneous vaginal delivery after successful MR (Table 5).

\subsection{Technique and Success Rate}

The success rate varied from $47 \%$ to $93.3 \%$ (Table 6). Two main techniques, MR and DR, were used in the studies. Some of the studies used MR or DR as the main term for the rotation procedure, even though the other technique was also performed.

\section{Interpretations of Findings}

Having studied the results it appears that the choice of technique does not have a major influence on the success rate.

\subsection{Midwives' Involvement in Manual Rotation}

In all of the included studies midwives supervised the labour and attended the physician performing MR. Midwives who experienced in MR also performed the procedure in all studies, with the exception of Sen et al. [31] and Graham et al. [28].

\subsection{Predictors of Successful or Unsuccessful Manual Rotation}

MR has the best chance of success when performed at full dilatation [13] after engagement of the head [13] [31] and when done prophylactically before failure to progress [13] (Table 7).

\section{Discussion}

This literature review investigated how MR can reduce VD, FD and CD. Based on the inclusion criteria, we identified seven quantitative studies from France, Israel, the USA, Japan and Australia that investigate this issue. MR was considered after diagnosis of an OP or OT position during labour at a dilatation of at least $7 \mathrm{~cm}$. A thematic analysis was conducted in accordance with the method described by Aveyard [24]. Six themes emerged: How can MR reduce VD, FD and $\mathrm{CD}$ ? Mode of delivery after MR versus expectant management; Mode of delivery after successful or unsuccessful MR; Technique and success rate; Midwives' involvement in MR; and Predictors of successful or unsuccessful MR, all of which are important for determining how MR can reduce VD, FD and CD. 
Table 6. Technique and success rate.

\begin{tabular}{|c|c|c|}
\hline $\begin{array}{l}\text { Main author } \\
\text { (year) country }\end{array}$ & Technique & $\begin{array}{l}\text { Rate of Successful } \\
\text { rotations }\end{array}$ \\
\hline $\begin{array}{l}\text { Shaffer (2006) } \\
\text { USA }\end{array}$ & $\begin{array}{l}\text { No technique described, but in Shaffer 2011, which is based on the same study material, the technique } \\
\text { was described. }\end{array}$ & $74 \%$ \\
\hline $\begin{array}{l}\text { Le Ray (2007) } \\
\text { France }\end{array}$ & $\begin{array}{l}\text { When the uterus is relaxed, the operator places two fingers or the entire hand (right hand for left OP and } \\
\text { OT-position and left hand for right OP and OT-position) behind the fetal ear. } \\
\text { During contraction, while the patient is pushing, the operator uses the pressure of the fingers to rotate } \\
\text { the anterior fetal head, moving the occiput relative toward the anterior pelvic girdle. } \\
\text { Continuously monitored fetal heart rate throughout the procedure. }\end{array}$ & $90.3 \%$ \\
\hline & $\begin{array}{l}\text { The DR technique accounted for } 97 \% \text { of the rotations. The rest of the rotations were based on the MR } \\
\text { technique. }\end{array}$ & \\
\hline $\begin{array}{l}\text { Reichman } \\
(2008) \\
\text { Israel }\end{array}$ & $\begin{array}{l}\text { DR entails exerting pressure with the tip of the fingers to rotate the posterior fontanelle upward, toward } \\
\text { the symphysis pubis after placing the tips of the index and middle fingers onto the edge of the part of the } \\
\text { anterior parietal bone that overlaps the occipital bone, the posterior fontanelle. } \\
\text { MR involves placing the whole hand in the birth canal, positioning the fingers under the lateral posterior } \\
\text { parietal bone and the thumb on the anterior parietal bone. The head is then rotated. }\end{array}$ & $93.3 \%$ \\
\hline $\begin{array}{l}\text { Shaffer (2011) } \\
\text { USA }\end{array}$ & $\begin{array}{l}\text { One of two techniques: } \\
\text { The first technique comprises placing the tips of the index and middle fingers onto the edge of the } \\
\text { anterior parietal bone that overlaps the occipital bone, followed by rotation of the posterior fontanelle } \\
\text { upwards towards the symphysis during a contraction or maternal expulsive efforts. } \\
\text { The second technique involves cradling the occiput with the fingers under the lateral posterior parietal } \\
\text { bone, with the thumb on the anterior parietal bone. Then slightly elevate using gentle pressure, rotate to } \\
\text { OA and flex the foetal occiput. }\end{array}$ & $74 \%$ \\
\hline $\begin{array}{l}\text { Le Ray (2013) } \\
\text { France }\end{array}$ & $\begin{array}{l}\text { When the uterus is relaxed, the operator places two fingers or the entire hand (right hand for left OP and } \\
\text { OT position and left hand for right OP and OT position) behind the foetal ear. } \\
\text { During contraction, while the patient is pushing, the operator uses the pressure of the fingers to rotate } \\
\text { the anterior foetal head, moving the occiput relative toward the anterior pelvic girdle. } \\
\text { Continuous monitoring of the foetal heart rate throughout the procedure. }\end{array}$ & $90.1 \%$ \\
\hline $\begin{array}{l}\text { Sen }(2013) \\
\text { Japan }\end{array}$ & No technique described. & $47 \%$ \\
\hline $\begin{array}{l}\text { Graham } \\
\text { (2014) Australia }\end{array}$ & $\begin{array}{l}\text { DR fingers placed on the lambdoid sutures, rotating towards the pubic symphysis during contraction } \\
\text { and with expulsive effort over three contractions. Flexion force was applied, to correct any deflexion. } \\
\text { The head of the foetus was then held in OA position for further one to two contractions. }\end{array}$ & $60 \%$ \\
\hline
\end{tabular}

Digital Rotation $=$ DR, Occiput Posterior $=$ OP, Occiput Transverse $=$ OT, Occiput Anterior $=$ OA, Manual Rotation $=$ MR.

Table 7. Predictors of successful or unsuccessful MR.

\begin{tabular}{|c|c|c|c|}
\hline $\begin{array}{l}\text { Main author } \\
\text { (year) country }\end{array}$ & $\begin{array}{l}\text { Obstetric predictors of successful } \\
\text { or unsuccessful MR }\end{array}$ & $\begin{array}{c}\text { Maternal predictors of } \\
\text { successful or unsuccessful MR }\end{array}$ & $\begin{array}{l}\text { Other predictors of } \\
\text { successful or unsuccessful MR }\end{array}$ \\
\hline $\begin{array}{l}\text { Shaffer } \\
2006 \text { USA }\end{array}$ & $\begin{array}{l}\text { Labour induction and EDA were associated with } \\
\text { higher rates of } \mathrm{CD} \text {, but none of these factors } \\
\text { increased the rate of failed rotation. }\end{array}$ & $\begin{array}{l}\text { Multipara women and women } \\
\text { under } 35 \text { years were more likely to } \\
\text { have a successful MR. }\end{array}$ & No Data \\
\hline $\begin{array}{l}\text { Le Ray } 2007 \\
\text { France }\end{array}$ & $\begin{array}{l}\text { Attempted rotation before full dilatation tripled } \\
\text { the risk of failure compared with rotation at full } \\
\text { dilatation. } \\
\text { MR for failure to progress increased the risk of } \\
\text { failure compared with prophylactic rotation. } \\
\text { No engagement (above station } 0 \text { ) increased the } \\
\text { risk of failure. }\end{array}$ & $\begin{array}{l}\text { Nulliparity and age }>35 \text { were risks } \\
\text { of failure. }\end{array}$ & $\begin{array}{l}\text { Risk factors for failure increased with the } \\
\text { number of attempts. } 69.6 \% \text { succeeded on } \\
\text { the first occasion, but none of the fourth } \\
\text { or fifth attempts were successful. } \\
\text { MR at night failed twice as often } \\
\text { compared with during the day }\end{array}$ \\
\hline $\begin{array}{l}\text { Sen } 2013 \\
\text { Japan }\end{array}$ & $\begin{array}{l}\text { MR has a better chance of success if the foetal } \\
\text { head is at station } 0 \text {, or further down. }\end{array}$ & & $\begin{array}{l}\text { There was no significant difference } \\
\text { between the successful rotation rate when } \\
\text { MR and Posture change were compared. }\end{array}$ \\
\hline
\end{tabular}

Epidural $=\mathrm{EDA}$, Caesarean Delivery $=\mathrm{CD}$, Manual Delivery $=\mathrm{MR}$. 


\subsection{Mode of Delivery and Models of Care}

All of the included studies suggest MR as a procedure to consider for reducing $\mathrm{VD}, \mathrm{FD}$ and $\mathrm{CD}$ rates.

The main aim of midwives and obstetricians in maternity care is to protect the health of mother and child. The two professions are based on two fundamentally different models of care [32]. Midwives are responsible for normal labours, due to their expertise in protecting, supporting and enhancing the normal physiology of labour [32]. Physicians have a background in medicine and are responsible for the pathologic aspects of labour, with often involve diagnosing and treating complications [32]. In reality, despite the fact that these two basic differences are non-debatable, the two professions share information, expert opinions and research, working together to holistically safeguard both the physiological and the pathological labour.

Labours with OP and OT positions often start normally but pathology can develop during the process. These malpositions are diversities of foetal rotation and while not pathological, involve a risk of pathology. Obstetricians and midwives work together to protect the health of mother and child, but how to manage an individual labour and decide when to intervene can be a subject of debate, especially between midwives and obstetricians.

It is relevant to argue that most OP positions rotate spontaneously and for that reason expectant management is the best approach. Nevertheless, OP and OT positions are associated with a greater risk of prolonged second stage labour and maternal morbidity [1]. As many as 5.5 to $8.3 \%$ of OP positions are persistent [5] [16] of which 68\% require an OD [3]. Many OP positions rotate during the first stage of labour [15].

Le Ray et al. [13] and Sen et al. [31] state that a predictor of successful MR is performing the procedure at full dilatation. This indicates that MR should be performed in stage two of labour, at which point many of the OP presentations that spontaneously rotate have already done so. Le Ray et al. [13] found that MR has a better chance of success when performed prophylactically before failure to progress. In expectant management, the indication for MR is likely to be failure to progress, which reduces the chance of successful MR.

Because midwives are responsible for monitoring normal labours and most labours with OP and OT positions start normally, it is their duty to diagnose the OP or OT position. Many midwives believe that expectant management is the best way to manage labour because they understand it as a normal physiological process and therefore try to avoid unnecessary interventions. However, for expectant management to support natural physiological labour it is necessary to monitor the rotation and presentation of the foetus when assessing progress. The results from the included studies show a reduction in the OD rate and an increase of SVD after MR versus expectant management (Table 4). For this reason MR can contribute to protecting, supporting and enhancing the normal physiology of labour by facilitating SVD.

Midwives' and physicians' different models of care [32] can also have conse- 
quences for the mode of delivery, in that a midwife performs MR to support and enhance the normal physiology of labour. In other words, the midwife performs MR and then waits to see if the labour proceeds normally, as this is the basic philosophy of the midwifery profession. On the other hand, obstetricians might find it easier to convert the MR procedure into an ID due to their underling expectation to treat and the fact that performing obstetric interventions is their area of expertise. This can explain the high level of ID after successful rotations in Le Ray et al. [13].

\subsection{Technique and Experience}

The included studies demonstrate the great importance of successful MR for reducing VD, FD and CD (Table 6). For this reason, we investigated the predictors of successful rotation, only to find that none of the studies highlighted the actual MR technique as a predictor of success. As MR is a handcraft with wide interpretations, it was interesting to explore the different techniques used and the success rate in each study (Table 5). However, the choice of technique did not seem to influence the success rate and instead experience appears to be the decisive factor. In most studies experienced personnel performed MR or supervised less experienced colleagues. This is a traditional and valuable way of working as it provides inexperienced personnel with hands on experience, an opportunity to ask about the procedure and receive advice [33]. However, gaining experience requires midwives and physicians to perform MR. Two large surveys were conducted in Australia and New Zealand to increase understanding of midwives' and obstetricians' attitudes towards MR [34] [35]. It was found that while only a minority of obstetricians and midwives perform MR, most consider the procedure acceptable. Midwives and Obstetricians would be willing to perform MR if it was known to decrease OD from $68 \%$ to a median of $50 \%$. From my own experience as a midwife, I believe that this survey is relevant and also reflects Norwegian Midwives' and Obstetricians' attitudes towards MR. Experience is of great importance for achieving the best possible results in most handcrafts [7]. Le Ray et al. [13] states that the low failure rate in the study is probably related to the efficacy of this technique when used routinely.

\subsection{Midwives' Role in Labour and Involvement in the Manual Rotation Procedure}

$\mathrm{OP}$ and OT positions are associated with a prolonged first and second stage of labour [1] [5]. Admission to the maternity ward can be a long and painful experience for the woman and a challenge for the midwife. In addition to emotional support, the midwife provides pain relief and information, as well as monitoring the progress of both mother and foetus. Recent research confirms that continuous care in labour contributes to increased SVD, decreases the need for analgesia, leads to less dissatisfaction and can reduce the need for $\mathrm{CD}$ and instrumental delivery [23]. There are many ways of supporting women in labour. The best support is dependent on what becomes a challenge in each individual labour and the 
woman's motivation and resources, both physical and psychological. The study on continuous support for women during childbirth [23] does not define the concept. Other than suggesting that it can be emotional support, comforting measures, information and advocacy, it was also stated that the best support was given by someone other than hospital staff. This indicates that the midwife's special competence regarding the labour process may not be the only support needed to facilitate spontaneous vaginal delivery. However, because of the risk factors involved, when faced with OP or OT positions, the midwife's competence is important for providing adequate comfort measures, information and advocacy to prevent maternal complications or to support the woman when the obstetrician has to intervene. Few other professions in the obstetric field work as close to the individual women in labour, which gives midwives a huge advantage in terms of their responsibility to monitor the birth process and therefore also the rotation of the foetus during labour. A diagnosis of OP position made early in labour is important because the MR rotation may be easier to perform before the labour fails to progress [13]. The midwife attending the labour can perform the MRor in the event of lacking the necessary skill, can ensure that the situation is evaluated at the right time by a midwife or an obstetrician with competence in performing MR.

Midwives supervised labours and attended doctors performing MR in all of the included studies. They also performed MR in all studies with the exception of Sen et al. [31] and Graham et al. [28].

\subsection{Limitations of this Review}

This literature review has several limitations. A meta-analysis was not possible due to the diversity of the aims, design and population in the included studies [24]. None of the studies were RCTs and of the seven included studies, only three had a high methodological quality. When conducting a review, the researcher is in danger of making choices regarding the selection of studies and data extraction that could lead to the risk of bias [36].

\section{Conclusion}

In conclusion, a successful MR can reduce $\mathrm{CD}$ rates and facilitate spontaneous vaginal delivery. However, experience is necessary to achieve successful rotations. MR is worth considering as there are few risk factors involved.

\section{Implications for Practice}

It is important that midwives diagnose the OP or OT position early in labour so that MR can be considered at the right time, thus increasing the chances of success. Midwives have the benefit of being close to the individual women, enabling them to evaluate the progress of labour and therefore the rotation of the foetus. Midwives have a great opportunity to achieve high competence in this area and may prevent labours with malposition from developing a pathological pattern. However, to make MR a safe treatment option there is a need for training pro- 
grammes that focus on diagnosing foetal position and presentation.

It is also essential that the documentation during labour is designed to include the position and presentation of the foetus in the same way as it requires information on dilatation and descent of the foetal head. This will make diagnosing the foetal position a necessity when documenting all labours, which implies that midwives will have to develop or improve their skills.

When it comes to making MR a routine treatment option, an important implication for practice is positive commitment from midwives and doctors. Commitment and focus are required in order to ensure that diagnosis of foetal position and presentation becomes a natural part of evaluating the progress of labour.

There is also a need for RCTs to verify the results of the studies in this review. Two double-blinded multicentre RCTs are now being conducted in Australia [37] [38] that may provide results that can be incorporated into professional guidelines for obstetricians and midwives.

\section{Acknowledgements}

The authors acknowledge Signy Solberg, Toril Hestnes and all the helpful people at the University of Oslo Library, Medical Library, and Ullevål Hospital with guidance on the systematic search process and the End Note library. We would also like to thank Annsofie Adolfsson and Aase Serine Devold Pay with necessary feedback and suggestions on improvements along the way as well as Monique Federsel for reviewing the English language of the final product. The study was partly funded by the University College of Southeast-Norway.

\section{Contributors}

The study was designed by C.O. The report was written by C.O. E.S. supervised the study.

\section{Conflicts of Interest}

The author's declare there are no conflicts of interest.

\section{References}

[1] Senecal, J., Xiong, X. and Fraser, W.D. (2005) Effect of Fetal Position on SecondStage Duration and Labor Outcome. The American College of Obstetricians and Gynecologists, 105, 763-772. https://doi.org/10.1097/01.aog.0000154889.47063.84

[2] Phillips, R.D. and Freeman, M. (1974) The Management of the Persistent Occiput Posterior Position. A Review of 552 Consecutive Cases. Obstetrics \& Gynecology, 43, 171-177. http://journals.lww.com/greenjournal/Abstract/1974/02000/The_Management_of_t he Persistent Occiput Posterior.2.aspx

[3] Carseldine, W.J., Phipps, H., Zawada, S.F., Campbell, N.T., Ludlow, J.P. and Krishnan, S.Y. (2013) Does Occiput Posterior Position in the Second Stage of Labour Increase the Operative Delivery Rate? Australian and New Zealand Journal of Obstetrics and Gynaecology, 53, 265-270. https://doi.org/10.1111/ajo.12041 
[4] Fitzpatrick, M., Mcquillan, K. and O'Herlihy, C. (2001) Influence of Persistent Occiput Posterior Position on Delivery Outcome. The American College of Obstetricians and Gynecologists, 98, 1027-1031.

[5] Ponkey, S.E., Cohen, A.P., Heffner, L.J. and Lieberman, E. (2003) Persistent Fetal Occiput Posterior Position: Obstetric Outcomes. The American College of Obstetricians and Gynecologists, 101, 915-920. https://doi.org/10.1097/00006250-200305000-00016

[6] Bahl, R., Van De Venne, M., Macleod, M., Strachan, B. and Murphy, D.J. (2013) Maternal and Neonatal Morbidity in Relation to the Instrument Used for MidCavity Rotational Operative Vaginal Delivery: A Prospective Cohort Study. BJOG: An International of Journal of Obstretic \& Gynaecology, 120, 1526-1532. https://doi.org/10.1111/1471-0528.12398

[7] O'Mahony, F., Hofmeyr, G.J. and Menon, V. (2010) Choice of Instruments for Assisted Vaginal Delivery. Cochrane Database of Systematic Reviews, Cd005455.

[8] Cunningham, F.G. and Williams, J.W. (2001) Williams Obstetrics. 21st Edition, McGraw-Hill, New York.

[9] Belfort, M.A. (2003) Operative Vaginal Delivery. In: Danforth, D.N. and Scott, J.R. Eds., Danforth's Obstetrics and Gynecology, 9th Edition, Lippincott Williams \& Wilkins, Philadelphia, 419-447.

[10] Tarnier, E. and Budin, P. (1888) Traité de l'art des accouchements. Vol. 2, G. Steinheil, Paris. http://gallica.bnf.fr/ark:/12148/bpt6k5817614g

[11] Jain, V., Guleria, K., Gopalan, S. and Narang, A. (1993) Mode of Delivery in Deep Transverse Arrest. International Journal of Gynecology and Obstetrics, 43, 129135. https://doi.org/10.1016/0020-7292(93)90319-R

[12] Cargill, Y.M., Mackinnon, C.J., Arsenault, M.Y., Bartellas, E., Daniels, S. and Gleason, T. (2004) Guidelines for Operative Vaginal Birth. Journal of Obstetrics and Gynaecology, 26, 747-761. https://doi.org/10.1016/S1701-2163(16)30647-8

[13] Le Ray, C., Serres, P., Schmitz, T., Cabrol, D. and Goffinet, F. (2007) Manual Rotation in Occiput Posterior or Transverse Positions: Risk Factors and Consequences on the Cesarean Delivery Rate. The American College of Obstetricians and Gynecologists, 110, 873-879.

[14] Shaffer, B.L., Cheng, Y.W., Vargas, J.E. and Caughey, A.B. (2011) Manual Rotation to Reduce Caesarean Delivery in Persistent Occiput Posterior or Transverse Position. The Journal of Maternal-Fetal and Neonatal Medicine, 24, 65-72. https://doi.org/10.3109/14767051003710276

[15] Akmal, S., Tsoi, E., Howard, R., Osei, E. and Nicolaides, K.H. (2004) Investigation of Occiput Posterior Delivery by Intrapartum Sonography. Ultrasound in Obstetrics and Gynecology, 24, 425-428. https://doi.org/10.1002/uog.1064

[16] Cheng, Y.W., Shaffer, B.L. and Caughey, A.B. (2006) Associated Factors and Outcomes of Persistent Occiput Posterior Position: A Retrospective Cohort Study from 1976 to 2001. The Journal of Maternal-Fetal and Neonatal Medicine, 19, 563-568. https://doi.org/10.1080/14767050600682487

[17] Ye, J., Zhang, J., Mikolajczyk, R., Torloni, M.R., Gulmezoglu, A.M. and Betran, A.P. (2015) Association between Rates of Caesarean Section and Maternal and Neonatal Mortality in the 21st Century: A Worldwide Population-Based Ecological Study with Longitudinal Data. BJOG: An International Journal of Obstetrics \& Gynaecology, 123, 745-753.

[18] Norwegian Institute of Public Health. https://www.fhi.no/en/

[19] Oyelese, Y. and Smulian, J.C. (2006) Placenta Previa, Placenta Accreta, and Vasa 
Previa. The American College of Obstetricians and Gynecologists, 107, 927-941.

[20] Smith, G.C., Pell, J.P. and Dobbie, R. (2003) Caesarean Section and Risk of Unexplained Stillbirth in Subsequent Pregnancy. The Lancet, 362, 1779-1784. https://doi.org/10.1016/S0140-6736(03)14896-9

[21] Macara, L.M. and Murphy, K.W. (1994) The Contribution of Dystocia to the Cesarean Section Rate. American Journal of Obstetrics and Gynecology, 171, 71-77. https://doi.org/10.1016/S0002-9378(94)70080-X

[22] Brown, H.C., Paranjothy, S., Dowswell, T. and Thomas, J. (2013) Package of Care for Active Management in Labour for Reducing Caesarean Section Rates in LowRisk Women. The Cochrane Database of Systematic Reviews, 9, Cd004907. https://doi.org/10.1002/14651858.cd004907.pub3

[23] Hodnett, E.D., Gates, S., Hofmeyr, G.J. and Sakala, C. (2013) Continuous Support for Women during Childbirth. The Cochrane Database of Systematic Reviews, 7, Cd003766. https://doi.org/10.1002/14651858.cd003766.pub5

[24] Aveyard, H. (2014) Doing a Literature Review in Health and Social Care. 3rd Edition, Open University Press, Maidenhead.

[25] Casp, C. (2014) Critical Appraisal Skills Programme (CASP). http://www.casp-uk.net/criticalappraisal

[26] Berg, R.C., Denison, E.M.-L. and Fretheim, A. (2010) Factors Promoting and Hindering the Practice of Female Genital Mutilation/Cutting (FGM/C). No. 23, Report from the Norwegian Knowledge Centre for the Health Services, 1-102.

[27] Shaffer, B.L., Cheng, Y.W., Vargas, J.E., Laros, R.K.J. and Caughey, A.B. (2006) Manual Rotation of the Fetal Occiput: Predictors of Success and Delivery. American Journal of Obstetrics and Gynecology, 194, e7-e9. https://doi.org/10.1016/j.ajog.2006.01.029

[28] Graham, K., Phipps, H., Hyett, J.A., Ludlow, J.P., Mackie, A. and Marren, A. (2014) Persistent Occiput Posterior: OUTcomes Following Digital Rotation: A Pilot Randomised Controlled Trial. Australian and New Zealand Journal of Obstetrics and Gynaecology, 54, 268-274. https://doi.org/10.1111/ajo.12192

[29] Le Ray, C., Deneux-Tharaux, C., Khireddine, I., Dreyfus, M., Vardon, D. and Goffinet, F. (2013) Manual Rotation to Decrease Operative Delivery in Posterior or Transverse Positions. The American College of Obstetricians and Gynecologists, 122, 634-640. https://doi.org/10.1097/aog.0b013e3182a10e43

[30] Reichman, O., Gdansky, E., Latinsky, B., Labi, S. and Samueloff, A. (2008) Digital Rotation from Occipito-Posterior to Occipito-Anterior Decreases the Need for Cesarean Section. European Journal of Obstetrics and Gynecology and Reproductive Biology, 136, 25-28. https://doi.org/10.1016/j.ejogrb.2006.12.025

[31] Sen, K., Sakamoto, H., Nakabayashi, Y., Takeda, Y., Nakayama, S. and Adachi, T. (2013) Management of the Occiput Posterior Presentation: A Single Institute Experience. The Journal of Obstetrics and Gynaecology Research, 39, 160-165. https://doi.org/10.1111/j.1447-0756.2012.01935.x

[32] Rooks, J.P. (1999) The Midwifery Model of Care. Journal of Nurse-Midwifery, 44, 370-374. https://doi.org/10.1016/S0091-2182(99)00060-9

[33] Benner, P. (2011) Formation in Professional Education: An Examination of the Relationship between Theories of Meaning and Theories of the Self. The Journal of Medicine and Philosophy, 36, 342-353. https://doi.org/10.1093/jmp/jhr030

[34] Phipps, H., De Vries, B., Lee, P.N. and Hyett, J.A. (2012) Management of Occiput Posterior Position in the Second Stage of Labour: A Survey of Obstetric Practice in Australia and New Zealand. Australian and New Zealand Journal of Obstetrics and 
Gynaecology, 52, 450-454. https://doi.org/10.1111/j.1479-828X.2012.01458.x

[35] Phipps, H., De Vries, B., Jagadish, U. and Hyett, J. (2014) Management of Occiput Posterior Position in the Second Stage of Labor: A Survey of Midwifery Practice in Australia. Birth, 41, 64-69. https://doi.org/10.1111/birt.12094

[36] Schneider, Z., Whitehead, D. and Elliott, D. (2007) Nursing \& Midwifery Research: Methods and Appraisal for Evidence-Based Practice. 3rd Edition, Mosby Elsevier, Sydney.

[37] De Vries, B., Phipps, H., Kuah, S., Pardey, J., Ludlow, J. and Bisits, A. (2015) Transverse Occiput Position: Using Manual Rotation to Aid Normal Birth and Improve Delivery Outcomes (TURN-OUT): A Study Protocol for a Randomised Controlled Trial. Trials, 16, 362. https://doi.org/10.1186/s13063-015-0854-3

[38] Phipps, H., Hyett, J.A., Kuah, S., Pardey, J., Ludlow, J. and Bisits, A. (2015) Persistent Occiput Posterior Position-OUTcomes Following Manual Rotation (POP-OUT): Study Protocol for a Randomised Controlled Trial. Trials, 16, 96.

https://doi.org/10.1186/s13063-015-0603-7

\section{Submit or recommend next manuscript to SCIRP and we will provide best service for you:}

Accepting pre-submission inquiries through Email, Facebook, LinkedIn, Twitter, etc. A wide selection of journals (inclusive of 9 subjects, more than 200 journals)

Providing 24-hour high-quality service

User-friendly online submission system

Fair and swift peer-review system

Efficient typesetting and proofreading procedure

Display of the result of downloads and visits, as well as the number of cited articles

Maximum dissemination of your research work

Submit your manuscript at: http://papersubmission.scirp.org/

Or contact ojn@scirp.org 